\title{
Combining employment with unpaid caregiving: a survey on the knowledge and use of work policies in two companies in The Netherlands
}

\author{
Nicolle Boumans (Corresponding author) \\ Assistant Professor, Department of Social Medicine \\ Maastricht University, Netherland \\ Email: nicolle.boumans@maastrichtuniversity.nl
}

Elisabeth Dorant

Assistant Professor, Department of Social Medicine

Maastricht University, Netherland

Email: elisabeth.dorant@maastrichtuniversity.nl

Doi:10.5296/ijhrs.v5i3.7396 URL: http://dx.doi.org/10.5296/ijhrs.v5i3.7396

\begin{abstract}
The number of informal caregivers who combine employment with unpaid care for an ill/disabled family acquaintance is growing. Employers are challenged to create conditions for a work-home balance for their caring employees. We identified the nature of formal leave policies and informal means of organizational support for employed carers in two Dutch companies. In 2011 we distributed a digital questionnaire among all employees in one health care and one financial company. Compared to their non-caring colleagues, in both companies the caring employees only make more use of formal leave arrangements. Neither organization offers special support measures. In both companies the caregivers value the informal support at the workplace. Organizations should offer a broad variety of formal workplace policies with customized solutions for the diverse and often unpredictable caring situations their employees are confronted with in their private lives. The formal leave system should be intensified by the informal organizational culture.
\end{abstract}

Keywords: Family caregivers, workplace policies, work-life balance, organizational culture, health care sector, private sector 


\section{Introduction}

In the Netherlands about 3.7 million people of 18 years and older provide informal care (De Boer, Broese van Groenou and Timmermans 2009). In 2008 over $71 \%$ of the informal caregivers combined the caregiving tasks with paid employment (Oudijk, De Boer, Woittiez, Timmermans and De Klerk 2010). Van Kesteren (2009) assumes that nearly one in eight Dutch employees takes care of a partner, family member or friend. Oudijk et al. (2010) also showed that in 2008 in the Netherlands approximately $60 \%$ of the informal caregivers were women and that almost half of these caregivers were aged between 45 and 65 years. Data from the 2005 Labor Force Survey (LFS) ad hoc module show an EU employment rate of $59.2 \%$ for carers of working age (people regularly taking care of ill, disabled or elderly relatives or friends aged 15 years or more), ranging from a low of $37.8 \%$ in Malta to a high of $72.7 \%$ in Sweden (2009).

The number of informal caregivers is expected to increase further owing to a number of demographic, social and economic developments. As in other advanced countries the extension of life expectancy and reduced birth rate resulted in an ageing Dutch population. As a consequence, the Netherlands are confronted with escalating health care costs and the urge to make choices in the spending of limited resources. The coalition agreement Rutte II (Rutte and Samson 2012) is estimated to have reaching consequences for the Dutch informal caregivers. In the coming years there will be a substantial saving of about 5 milliard euro on health care facilities. An expected consequence of radical changes in health care legislation and a diminution in the range of professional care is that chronically ill and disabled people increasingly rely on family, friends and neighbors for voluntary care and support (2012). With the stretching of the retirement age from 65 to 67 years, the need to extend the participation of older workers in the labor force is to a certain degree in conflict with this growing dependence on family and friends to care for a family member or close friend in need.

Published research in the field of working caregivers and types of employer-level answers is dominated by United States and to a lesser degree UK sources, although there are an increasing number of studies from other countries as Finland, Germany and Belgium (2011). The systematic review of Lilly, Laporte and Coyte (2007) revealed that family caregiving is associated with reduced rates of work participation, both in terms of the ability to keep paid employment and in terms of the number of hours worked. The study of Kotsadam (2011) found that throughout the European Union the employment of women is negatively associated with informal caregiving to the elderly. As the potential labor market is expected to shrink, preventing the job withdrawal of employees who care for dependents becomes a huge challenge for organizations in the near future. Besides this, the experienced burdens of employees who keep on trying to combine employment with informal caregiving can also have negative consequences for employers, such as reduced productivity, increased presenteeism and absenteeism (McBride-King 1999; De Vroome, Smulders and Houtman 2010). So, there is a great urgency for employers to develop and implement policies and practice in the workplace in order to support those who have caring responsibilities for older, sick or disabled relatives or friends. In the discussion on work-life balance attention mainly 
had focused on policies related to the care of young children, with relatively little attention to workers taking care of ill or disabled family members (Pavalko and Henderson 2006; Anderson 2003). It seems that specific provisions for working caregivers are a lot less common than provisions for working parents (Cullen and Gareis 2011). Informal caregivers of ill or disabled persons have different needs for support to enable them to combine employment with their caring tasks. Opposed to the care of children, which follows a reasonable predictable time and activity schedule, the care for the ill or disabled spouses or parents is rather varied and unpredictable in terms of time commitment. Furthermore, the amount and intensity of caring tasks increase over the course of the care period (Pavalko and Henderson 2006). This specific nature of care makes it difficult for employers to find useful policies that allow the necessary flexibility in work schedules.

There is a growing number of companies that offer formal policies, benefits and programs to optimize the work-life balance of their caring employees, ranging from measures to cover both planned (i.e. short and longer leave) and unplanned occurrences (i.e. emergency leave), carer-friendly working arrangements (i.e. flexibility in working hours, teleworking, part-time work, job share) and other support measures (i.e. financial benefits, information programs, counseling, carer network/support groups) (Barr, Johnson and Warshaw 1992; Philips, Bernard and Chittenden 2002; Arksey 2002; Yeandle, Wigfield, Crompton and Dennett 2002; Arksey and Glendinning 2008; Cullen and Gareis 2011).

Recently there is a growing recognition in the work-family literature that alongside formal measures informal means of organizational support are needed to guarantee an appropriate balance of work and family. According to Fine (2012) offering possibilities for care leave alone is insufficient. The study of Behson (2005) demonstrates that informal means of work-family support explain a greater share of variance in employee outcomes (i.e. job satisfaction, stress, turnover intentions) than formal mechanisms. It appears that unsupportive organizational cultures and managers may undermine the potential effectiveness of formal regulations. Also other authors point to the importance of supportive line managers and co-workers in a ,carer-friendly ${ }^{\text {ee }}$ organizational environment (Philips et al. 2002; Arksey 2002). From 44 in-depth interviews with working family carers Philips et al. (2002) identified four sets of factors that affect the way in which managers translate policy into practice: attitudes (manager discretion and support), knowledge of staff (e.g. being informed about someone's caregiving histories), balancing the complexity (e.g. balancing the needs of the carer versus the needs of the organization) and (,family-friendlye) subcultures in the organization. This finding underlines the importance of supervisors who have sympathy for the caring role of their subordinates and who are willing to apply and translate formal policies to the specific situation of the individual caregiver. This is only possible in a constructive and motivating organizational culture. Research into workplace cultures has shown that some workplaces are described by their employees as care friendly, while others in the same industry with the same work are regarded as hostile (Airey, McKie and Backett-Milburn 2007).

Company-level measures for employed carers often find their origin in employment and employment-related national and international legislation. In their report on company initiatives for workers with care responsibilities Cullen and Gareis (2011 conclude that there 
is currently no EU-level labor legislation that directly and concretely addresses working carers as such. At this moment leave provisions for working carers vary considerably across the EU member States in terms of nature and duration of leave, whether the leave is paid or unpaid, what types of carers are targeted and the amount of discretion left to the employer.

In the Netherlands the Work and Care Act (2013) provides for paid emergency and short-term leave (up to 10 working days per year), as well as unpaid longer-term leave to a maximum of about six weeks. Under separate provisions ("Levensloopregeling"), the opportunity of saving for a career break offers scope for putting aside funds to provide income during caring (Cullen and Gareis 2011).

The deployment and actual use of workplace policies may depend on type of organization, work and employee's function. From the study of Arksey (2002) it appeared that larger organizations were more likely to offer a variety of leave and flexible working arrangements which could support caregivers. According to Arksey (2002) there is also evidence that the public sector, which generally employs large numbers of women is ahead of industry and private business in developing policies to support staff with caring tasks. On the other hand, in the private sector, financial services organizations are predominantly active in developing formal family-friendly policies (Lewis 1999). Furthermore, Behson (2005) reported that employees in professional and managerial positions are more likely to meet family friendly supervision than those with more restrictive job types, such as blue-collar or clerical workers. Finally, in some jobs the use of working arrangements like flexibility in working hours and teleworking is very difficult because of activities which are highly time- or client-dependent, and part-time workers do not always have equal access to flexibility compared to full-time employees (Cullen and Gareis 2011).

Overall, like other EU countries the Netherlands are confronted with a growing number of informal carers who combine employment with taking care on a regular basis of ill, disabled or elderly family members or close friends. Dutch companies should be aware of the growing need of formal carer-friendly workplace strategies and policies. Besides these formal arrangements, being (partly) based on Dutch employment legislation as the Work and Care Act, it was noted that informal processes (i.e. supportive supervisors, colleagues and organizational culture) are shaping the necessary breeding grounds for the successful application of formal measures.

\section{Purpose of the study}

The aim of our study is to identify the nature of formal policies and programs and informal means of organizational support for employed informal caregivers in two different Dutch companies, one from the private sector, i.e. a company delivering financial services (i.e. financial company $=\mathrm{FC}$ ) and one from the public sector, i.e. a health care company (i.e. care company $=\mathrm{CC}$ ). In the private sector company mainly clerical workers are employed and in the public sector company the majority of employees are active in the position of health care professional. 


\section{$\Lambda$ Macrothink}

\section{Methods}

\subsection{Sample}

In this cross-sectional study data were collected by a self-administered digital questionnaire. All employees, including supervisors, of both companies were invited by email to participate in the survey. Those giving their consent were asked to complete the questionnaire in June 2011. Every employee was given a personal access code to the digital questionnaire on the organizational intranet.

In both organizations the study was approved by the appropriate committees, i.e. the participation council, and the data were anonymized, with careful protection on confidentiality. Participants were informed of the details of the study through an announcement on the organizational intranet and by their supervisors.

The health care company provides intra- and extramural healthcare services to people of all ages. The financial company delivers financial services in the field of insurances and pensions. The response rates differed considerably between the two participating organizations: $28.3 \%$ response for the care company $(n=446)$ and $47.8 \%(n=561)$ for the financial company. Noteworthy is that the great majority of employees in the care company is female $(92.7 \%)$, in the financial company only $48.1 \%$ is female.

Since we considered the discrepancies in these important variables (i.e. response rate and gender) between the two companies too large, we decided to perform descriptive analyses for each company separately, instead of comparing them directly.

\subsection{Measuring instrument}

The questionnaire consisted of a collection of structured scales to measure formal and informal support arrangements, supplemented with general demographic and employment characteristics. For those participants who identified themselves as informal caregiver for an ill, disabled or elderly relative or close friend a separate section with specific questions was added on caregiving specifics and personal experiences in combining work and unpaid caregiving. Finally, extra questions for supervisors and colleagues were added on the topic of unpaid caregiving in their organization.

\subsubsection{Demographic and employment characteristics}

The demographic and employment characteristics recorded included: age, gender, educational level, function, working schedule ( $\%$ of fixed hours), and number of working years for this employer, contract hours, and mean hours of overtime per week.

\subsubsection{Formal support arrangements:}

In both organizations we asked a specialist from the Human Resources Department to make a list of the company formal policies, benefits and programs the companies offer to their employees to stimulate their work-life balance. The respondents were asked about their familiarity and the use of these beneficial arrangements. For the health care organization we included all ten arrangements that were available to the employees, and for the financial 
company we included eight arrangements. For each arrangement, the respondents were asked to indicate whether or not they were familiar with this arrangement $(0=$ no; $1=y e s)$ and whether or not they made use of this arrangement $(0=$ no; $1=$ yes $)$.

\subsubsection{Informal support arrangements:}

For measuring the informal support experienced by the informal caregiver we focused on the organizational work-home culture (WHC), defined by Thompson, Beauvais and Lyness (1999) as "the shared assumptions, beliefs and values regarding the extent to which an organization supports and values the integration of employees "work and family lives" (p. 394). We used the WHC instrument developed by Dikkers et al. (Dikkers, Geurts, Den Dulk, Peper and Kompier 2004). The WHC is characterized by a two-dimensional structure, distinguishing between support and hindrance. The support dimension was measured by three subscales: (a) organizational support (employees ${ }^{e e}$ perceptions of how family-supportive the organization is) assessed by 5 items ( e.g., "In general, this company is considerate towards employeese private situation") (Cronbach's alpha is 0.85 ), (b) supervisor support (employees "eperceptions of how understanding the direct supervisor is of employees ${ }^{\text {ee }}$ desire to integrate work and private lives) assessed by 3 items (e.g., "My direct supervisor supports employees who want to switch to a less demanding job because of their private situation") (Cronbach 's alpha is 0.82), and (c) collegial support (employees ${ }^{\text {ee }}$ perceptions of how understanding the direct colleagues are of employees ${ }^{\text {ee }}$ desire to integrate work and private lives) assessed by 4 items (e.g., "My colleagues help me out if I am having a hard time coping with my caregiving situation") (Cronbach's alpha is 0.76). The hindrance dimension was measured by two subscales: (a) career consequences (the perception of negative career development as a consequence of the uptake of WH arrangements) (4 items, e.g., "Employees who turn down a promotion because of private circumstances wil suffer negative career consequences within this company"; Cronbach 's alpha is 0.79 ), and (b) organizational time demands (expectations that employees spend much time visibly at work) (3 items, e.g., "If necessary, employees within this company are expected to prioritize their work over their private situation"; Cronbach 's alpha is 0.85 ). Answer alternatives ranged from "totally disagree" (1) to "totally agree" (5).

Above this, we questioned the supervisors ${ }^{\text {ee }}$ and colleagues ${ }^{e}$ awareness with unpaid caregivers in their team with three items (response categories: ,yes ${ }^{\text {ee }}$,,no") (see table 6 for the items). Finally, the informal caregiving employees themselves were asked whether they were aware of being an unpaid caregiver and whether they had informed their supervisor and colleagues about their caregiving tasks (response categories: ,yes ${ }^{\mathrm{ee}}$, ,no $\mathrm{no}^{\mathrm{eq}}$ ( (see table 3 for the items).

\subsubsection{Specific questions for the informal caregivers}

In our questionnaire we included a separate set of questions exploring more specifically some characteristics of the informal care situation (i.e. the care receiver, the type of caring tasks performing, the hours of unpaid care per week and the years already providing unpaid care) and the caregivers ${ }^{\text {ee }}$ experiences with combining work and informal care. Three single items were assessed on a Likert scale with ranges 1-5 ("ability to combine work and informal care") or 1-4 ("work interruption due to caregiving task" and "experienced problems due to sudden 
interruptions").

\subsection{Data analyses}

Analyses were done using SPSS version 20.0 (IBM 2011). Per company three subgroups were formed based on the informal caregiver status. One group consisted of employees without additional informal caregiving activities (i.e. the non-informal caregivers), another group concerned the employees with informal caregiving tasks for less than 8 hours per week (i.e. the low intensity informal caregivers), and the last group included employees with 8 or more hours informal caregiving per week next to their paid caregiving tasks (i.e. the high intensity informal caregivers). The 8 hours cut-off point was chosen on the basis of the definition for informal care widely used in the Netherlands (De Boer, Schellingerhout and Timmermans 2003; Oudijk et al. 2010). It can be expected that the impact of the caregiving demands changes as the time spend caring increases (Chappel and Reid 2002; Farfan-Portet, Popham, Mitchell, Swine and Lorant 2009).

For each company descriptive analyses were performed separately (means, percentages, standard deviations). Per participating company, univariate ANOVA's were calculated to investigate the differences between the three groups (employees without informal caregiving, and the respectively low and high intensity informal caregivers) regarding their mean scores on the five WHC variables. For the $\mathrm{CC}$ we included age, working years and contract hours as covariates in the analyses, and for the FC age and gender, as significant differences between the three groups were found on these variables (see results section). In this study we used a statistical significance level of $\mathrm{p}<0.05$.

\section{Results}

\subsection{Participant characteristics}

Table 1 presents, per participating company, the scores on the demographical and employment characteristics for the three different groups of employees: those without additional informal caregiving tasks, and employees providing informal care for less than 8 hours per week (low intensity group), or for at least 8 hours per week (high intensity group). For the $\mathrm{CC}$ it appeared from the ANOVA's and $\mathrm{chi}^{2}$-tests that only age $(\mathrm{F}=12.06 ; \mathrm{p}=.001)$, contract hours $(\mathrm{F}=3.49 ; \mathrm{p}=.03)$ and working years $(\mathrm{F}=5.45 ; \mathrm{p}=.005)$ differed significantly between the three groups. Therefore, we entered these variables as covariates in the ANCOVA's for the WHC variables. For the FC we revealed significant differences for age $(\mathrm{F}=5.89 ; \mathrm{p}=.003)$ and gender $\left(\mathrm{chi}^{2}=15.96 ; \mathrm{p}=.001\right)$, therefore, we selected these two variables as covariates in the ANCOVA's for the FC.

Table 1 shows that in the CC $28 \%(n=125)$ of all respondents identified themselves as unpaid caregiver, while in the FC a lower percentage of $11.1 \%(\mathrm{n}=62)$ provided care for someone at home. In the CC the caregivers are older (mean age 48.1 years with more than $50 \%$ falling in the $45+$ categories in both low and high intensity subgroups), than in the FC (caregivers mean age 44.9 years). The gender distribution differed considerably between the two companies, as was mentioned before, but the difference per care category was most striking in the FC, with a higher percentage females in the low intensity care subgroup $(81.8 \%)$ and a higher 


\section{Macrothink}

International Journal of Human Resource Studies

ISSN 2162-3058

2015, Vol. 5, No. 3

percentage of males (55.2\%) in the high intensity care subgroup. The educational level of the participants in the $\mathrm{CC}$ as well as in the FC did not vary greatly between the three subgroups. Overall, employees in the FC were mostly highly educated. Furthermore, in the high care intensity group a difference was seen in household situation, with a higher percentage living with children in the $\mathrm{CC}$ than in the FC. In both companies the percentage of main wage earners was highest in the high intensity caregiver subgroups. Overall, there were more part-timers among the participants of the $\mathrm{CC}$ than of the $\mathrm{FC}$, with consequently lower contract hours. The number of working years for their employer is higher, in both companies, for both informal caregivers groups compared to the employees without informal caregiving tasks. In the $\mathrm{CC}$ the mean hours of overtime per week is rather comparable between the three groups. In the FC the number of overtime hours decreases as the hours of informal caregiving increases.

Table 1. Background characteristics participants of the non- ( $0 \mathrm{hrs} . / \mathrm{wk}$.$) , low (<8 \mathrm{hrs} . / \mathrm{wk}$. and high $(\geqslant 8 \mathrm{hrs} . / \mathrm{wk}$.) intensity informal caregiving groups from the care company (CC) and the financial company (FC).

\begin{tabular}{|c|c|c|c|c|c|c|}
\hline \multirow[t]{2}{*}{ Characteristics } & \multicolumn{3}{|l|}{$\mathrm{CC}$} & \multicolumn{3}{|l|}{ FC } \\
\hline & $0 \mathrm{hrs} / \mathrm{wk}$ & $<8 \mathrm{hrs} / \mathrm{wk}$ & $\begin{array}{l}\geq 8 \\
\mathrm{hrs} / \mathrm{wk}\end{array}$ & $0 \mathrm{hrs} / \mathrm{wk}$ & $\begin{array}{ll}< & 8 \\
\mathrm{hrs} / \mathrm{wk} & \end{array}$ & $\geq 8 \mathrm{hrs} / \mathrm{wk}$ \\
\hline & $n=321$ & $\mathrm{n}=66$ & $\mathrm{n}=59$ & $n=499$ & $\mathrm{n}=33$ & $\mathrm{n}=29$ \\
\hline Demographics & $\%$ & $\%$ & $\%$ & $\%$ & $\%$ & $\%$ \\
\hline \multicolumn{7}{|l|}{ Age (yrs) } \\
\hline$-\leq 34$ & 29.3 & 7.6 & 8.5 & 22.4 & 18.2 & 6.9 \\
\hline$-35-44$ & 19.3 & 13.6 & 27.1 & 40.3 & 33.3 & 27.6 \\
\hline$-45-54$ & 33.3 & 56.1 & 44.1 & 27.1 & 39.4 & 51.7 \\
\hline$-55+$ & 18.1 & 22.7 & 20.3 & 10.2 & 9.1 & 13.8 \\
\hline Gender (female) & 90.7 & 93.9 & 86.4 & 46.1 & 81.8 & 44.8 \\
\hline \multicolumn{7}{|l|}{ Educational level } \\
\hline - low & 26.5 & 22.7 & 20.3 & 14.6 & 24.2 & 24.1 \\
\hline - middle & 53.6 & 53.0 & 54.2 & 19.4 & 9.1 & 17.2 \\
\hline - high & 19.9 & 24.2 & 25.4 & 65.9 & 66.7 & 58.6 \\
\hline Living situation & & & & & & \\
\hline
\end{tabular}




\begin{tabular}{|c|c|c|c|c|c|c|}
\hline $\begin{array}{l}\text { - single household } \\
\text { - multiple household } \\
\text { - with children }\end{array}$ & $\begin{array}{l}13.4 \\
30.2 \\
56.4\end{array}$ & $\begin{array}{l}13.6 \\
31.8 \\
54.5\end{array}$ & $\begin{array}{r}1.7 \\
22.0 \\
76.3\end{array}$ & $\begin{array}{l}13.4 \\
24.2 \\
62.3\end{array}$ & $\begin{array}{l}9.1 \\
33.3 \\
57.6\end{array}$ & $\begin{array}{l}24.1 \\
27.6 \\
48.3\end{array}$ \\
\hline $\begin{array}{l}\text { Employment } \\
\text { characteristics }\end{array}$ & $\%$ & $\%$ & $\%$ & $\%$ & $\%$ & $\%$ \\
\hline Main wage earner & 32.1 & 27.3 & 32.2 & 71.5 & 45.5 & 79.3 \\
\hline $\begin{array}{l}\text { Full time } \\
\text { employment* }\end{array}$ & 12.8 & 6.1 & 16.9 & 26.1 & 27.3 & 17.2 \\
\hline & mean $(\mathrm{SD})$ & mean $(\mathrm{SD})$ & $\begin{array}{l}\text { mean } \\
(\mathrm{SD})\end{array}$ & $\begin{array}{l}\text { mean } \\
(\mathrm{SD})\end{array}$ & $\begin{array}{l}\text { mean } \\
(\mathrm{SD})\end{array}$ & $\begin{array}{l}\text { mean } \\
(\mathrm{SD})\end{array}$ \\
\hline Working years & $13.9(10.0)$ & $\begin{array}{l}17.7 \\
(10.8)\end{array}$ & $\begin{array}{l}17.1 \\
(9.4)\end{array}$ & $\begin{array}{l}11.6 \\
(9.8)\end{array}$ & $15.2(10.2)$ & $17.8(11.8)$ \\
\hline Contract hours & $25.0(7.4)$ & $22.3(7.8)$ & $\begin{array}{l}24.5 \\
(7.6)\end{array}$ & $\begin{array}{l}34.9 \\
(5.2)\end{array}$ & $32.7(7.7)$ & $34.2(5.7)$ \\
\hline Overtime hours & $1.6(2.6)$ & $1.7(2.4)$ & $\begin{array}{r}1.8 \\
(3.1)\end{array}$ & $2.8(3.9)$ & $1.8(2.7)$ & $1.0(2.1)$ \\
\hline
\end{tabular}

\subsection{Characteristics of the informal care situations and caregivers' experiences}

Table 2. Characteristics of the care situations of unpaid care givers of the low ( $<8 \mathrm{hrs}$./wk.) and high intensity care group ( $\geq 8 \mathrm{hrs}$./wk.) from the care company (CC) and the financial company (FC).

\begin{tabular}{|l|l|l|l|l|l|}
\hline Care characteristic & \multicolumn{2}{l|}{ CC } & \multicolumn{2}{l|}{ FC } \\
\hline & $<8 \mathrm{hrs} / \mathrm{wk}$ & $\geq 8 \mathrm{hrs} / \mathrm{wk}$ & & $<8 \mathrm{hrs} / \mathrm{wk}$ & $\geq 8 \mathrm{hrs} / \mathrm{wk}$ \\
\hline & $\mathrm{n}=66$ & $\mathrm{n}=59$ & & $\mathrm{n}=33$ & $\mathrm{n}=29$ \\
\hline & $\%$ & $\%$ & $\%$ & $\%$ \\
\hline
\end{tabular}




\begin{tabular}{|c|c|c|c|c|}
\hline \multicolumn{5}{|l|}{ Care receivers* } \\
\hline - partner & 3.0 & 22.0 & 2.7 & 22.5 \\
\hline - child & 9.1 & 27.1 & 10.8 & 22.5 \\
\hline - sibling & 3.0 & 8.5 & 5.4 & 6.5 \\
\hline - parent (in law) & 77.3 & 62.7 & 64.9 & 41.9 \\
\hline - friend & 6.1 & 1.7 & 2.7 & - \\
\hline - neighbor & 3.0 & - & - & - \\
\hline - other & 4.5 & 3.4 & 13.5 & 6.5 \\
\hline \multicolumn{5}{|l|}{ Caring task* } \\
\hline - domestic help & 40.9 & 47.5 & 13.3 & 18.9 \\
\hline - personal care & 16.7 & 47.5 & 2.7 & 10.8 \\
\hline - managerial activities & 68.2 & 88.1 & 37.3 & 28.4 \\
\hline - accompaniment & 75.6 & 89.8 & 25.3 & 35.1 \\
\hline \multirow[t]{2}{*}{ - other } & 1.5 & 1.7 & 10.6 & 6.8 \\
\hline & mean $(\mathrm{SD})$ & mean $(\mathrm{SD})$ & mean (SD) & mean $(\mathrm{SD})$ \\
\hline Hours care per week & $3.9(1.6)$ & $18.8(18.3)$ & $3.3(1.6)$ & $15.4(10.5)$ \\
\hline Years providing care & $8.8(8.7)$ & $11.0(8.4)$ & $\left(4.9^{7.7}\right.$ & $(8.8)^{9.1}$ \\
\hline $\begin{array}{l}\text { Total hours spend on work } \\
+ \text { unpaid care per week }\end{array}$ & $27.9(8.2)$ & $45.0(18.7)$ & $37.8(8.7)$ & $50.6(10.7)$ \\
\hline
\end{tabular}

Table 2 shows that, among the care recipients, parents and parents-in-law prevailed, in both subgroups, as well as in both companies. Furthermore, it shows, also for both companies, that a higher percentage in the high intensity caregivers takes care for someone close in the household, i.e. partner and/or child (CC is $49.1 \%$ and FC is $45 \%$ ) as compared to the low intensity carers ( $\mathrm{CC}$ is $12.1 \%$ and $\mathrm{FC}$ is $13.5 \%$ ). The mean number of different caring tasks per carer was higher in the $\mathrm{CC}$ than in the $\mathrm{FC}$, as can be seen from the higher percentages per caring task in the CC. Managerial care was frequently offered, as well as accompaniment to 
for instance the hospital or store. Markedly, a high percentage of employees from the CC offered personal care (ADL, support with medication) with the highest percentage of $47.5 \%$ found for the high intensity caregivers. As could be expected, the high intensity group in both companies, compared to the low intensity group, spends more hours of informal care per week, and is also providing this care for more years and spends more total hours on work and unpaid care per week.

Table 3. Views, actions, and experiences in combining work and unpaid caregiving of the low ( $<8 \mathrm{hrs}$./wk.) and high intensity care group ( $\geq 8 \mathrm{hrs}$./wk.) from the care company (CC) and the financial company (FC).

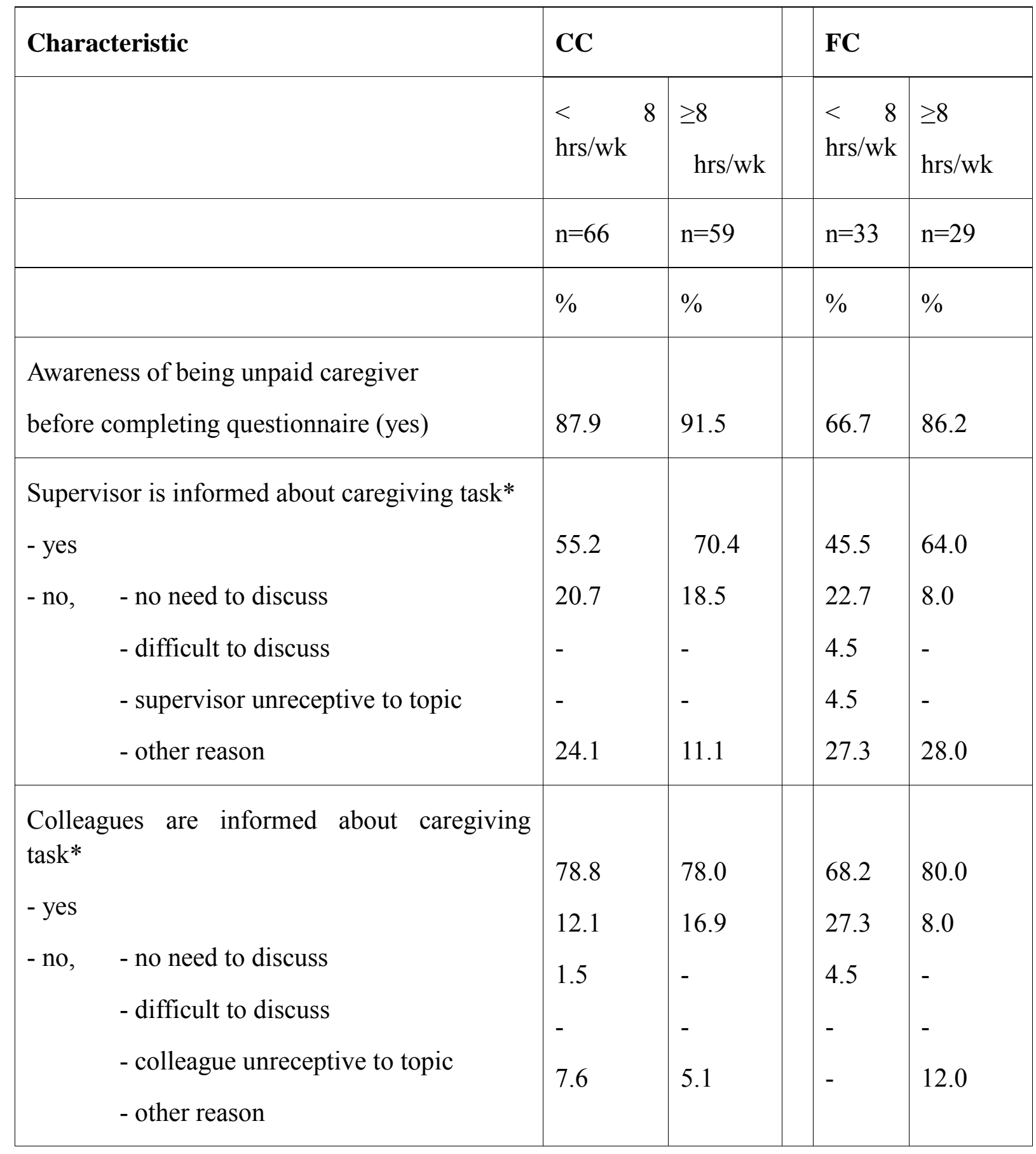




\begin{tabular}{|c|c|c|c|c|}
\hline & $\begin{array}{l}\text { mean } \\
(\mathrm{SD})\end{array}$ & $\begin{array}{l}\text { mean } \\
(\mathrm{SD})\end{array}$ & $\begin{array}{l}\text { mean } \\
(\mathrm{SD})\end{array}$ & $\begin{array}{l}\text { mean } \\
(\mathrm{SD})\end{array}$ \\
\hline Ability to combine work and unpaid care $(1-5)$ & $\begin{array}{r}3.83 \\
(0.67)\end{array}$ & $\begin{array}{r}3.32 \\
(0.47)\end{array}$ & $\begin{array}{r}3.79 \\
(0.74)\end{array}$ & $\begin{array}{l}3.62 \\
(0.56)\end{array}$ \\
\hline Work interruption due to caregiving task (1-4) & $\begin{array}{r}1.07 \\
(0.32)\end{array}$ & $\begin{array}{r}1.22 \\
(0.42)\end{array}$ & $\begin{array}{r}3.82 \\
(0.53)\end{array}$ & $\begin{array}{l}3.52 \\
(0.79)\end{array}$ \\
\hline $\begin{array}{l}\text { Experienced problems due to sudden } \\
\text { interruptions }(1-4)\end{array}$ & $\begin{array}{r}1.26 \\
(0.47)\end{array}$ & $\begin{array}{r}1.53 \\
(0.54)\end{array}$ & $\begin{array}{r}1.18 \\
(0.39)\end{array}$ & $\begin{array}{l}1.38 \\
(0.49)\end{array}$ \\
\hline $\begin{array}{l}\text { *: calculated for those being aware of their u } \\
\text { question }\end{array}$ & aid care & er role & eom & eting th \\
\hline
\end{tabular}

The mean scores on the three single items describing informal caregivers ${ }^{\text {ee }}$ experiences are presented in the last three rows of table 3. The ability to combine work and unpaid care did not vary greatly between the groups, in contrast with the work interruptions due to caregiving tasks, with higher means in the FC. However, the experiences of problems as consequence of these interruptions were low, and even lower than in the CC. 


\subsection{Formal support arrangements}

Table 4. Familiarity with and use of formal support arrangements of the non- ( 0 hrs./wk.), the low ( $<8 \mathrm{hrs}$./wk.) and high intensity care group ( $\geq 8 \mathrm{hrs}$./wk.) from the care company (CC) and the financial company (FC).

\begin{tabular}{|c|c|c|c|c|c|c|}
\hline & \multicolumn{6}{|l|}{$\mathbf{C C}$} \\
\hline \multirow[t]{3}{*}{ Type of workplace policy } & \multicolumn{2}{|c|}{$0 \mathrm{hrs} / \mathrm{wk}$} & \multicolumn{2}{|c|}{$<8 \mathrm{hrs} / \mathrm{wk}$} & \multicolumn{2}{|c|}{$\geq 8 \mathrm{hrs} / \mathrm{wk}$} \\
\hline & \multicolumn{2}{|c|}{$\mathrm{n}=321$} & \multicolumn{2}{|l|}{$\mathrm{n}=66$} & \multicolumn{2}{|c|}{$\mathrm{n}=59$} \\
\hline & know & use & know & use & know & use \\
\hline 1. part time work & 97.2 & 66.0 & 97.0 & 65.2 & 98.3 & 67.8 \\
\hline 2. short term care leave & 66.4 & 5.0 & 71.2 & 3.0 & 76.3 & 8.5 \\
\hline 3. long (unpaid) care leave & 59.2 & 1.9 & 62.1 & - & 66.1 & 1.7 \\
\hline 4. emergency leave & 52.0 & 6.2 & 68.2 & 12.1 & 57.6 & 11.9 \\
\hline 5. flexible hours & 70.4 & 24.0 & 78.8 & 28.8 & 71.2 & 32.2 \\
\hline 6. personal saving scheme* & 70.4 & 6.5 & 80.3 & 4.5 & 72.9 & 11.9 \\
\hline \multicolumn{7}{|l|}{ 7. teleworking } \\
\hline \multicolumn{7}{|l|}{ 8. personal budget** } \\
\hline 9. special care leave for serious illness & 58.6 & 2.2 & 68.2 & 4.5 & 64.4 & 8.5 \\
\hline 10.unpaid leave & 70.1 & 8.1 & 81.8 & 13.6 & 78.0 & 3.4 \\
\hline 11.(temporary) reduction in working hours & 62.9 & 13.1 & 72.7 & 13.6 & 62.7 & 27.1 \\
\hline \multirow[t]{2}{*}{ 12.(temporary) reduction in tasks } & 49.8 & 7.8 & 53.0 & 6.1 & 50.8 & 10.2 \\
\hline & \multicolumn{6}{|l|}{ FC } \\
\hline \multirow[t]{3}{*}{ Type of workplace policy } & \multicolumn{2}{|c|}{$0 \mathrm{hrs} / \mathrm{wk}$} & \multicolumn{2}{|c|}{$<8 \mathrm{hrs} / \mathrm{wk}$} & \multicolumn{2}{|c|}{$\geq 8 \mathrm{hrs} / \mathrm{wk}$} \\
\hline & \multicolumn{2}{|l|}{$\mathrm{n}=499$} & \multicolumn{2}{|l|}{$\mathrm{n}=33$} & \multicolumn{2}{|l|}{$n=29$} \\
\hline & know & use & know & use & know & use \\
\hline 1. part time work & 91.0 & 37.7 & 93.9 & 54.5 & 86.2 & 41.4 \\
\hline 2. short term care leave & 65.5 & 8.2 & 72.7 & 9.1 & 75.9 & 27.6 \\
\hline
\end{tabular}


3. long (unpaid) care leave

4. emergency leave

5. flexible hours

6. personal saving scheme*

7. teleworking

8. personal budget**

\begin{tabular}{|l|r|r|r|r|r|}
59.9 & 2.2 & 66.7 & 9.1 & 69.0 & 10.3 \\
49.7 & 7.2 & 57.6 & 3.0 & 51.7 & 3.4 \\
58.1 & 15.4 & 51.5 & 15.2 & 62.1 & 6.9 \\
90.2 & 10.8 & 87.9 & 3.0 & 89.7 & 3.4 \\
81.6 & 41.7 & 81.8 & 45.5 & 82.8 & 31.0 \\
88.4 & 50.5 & 87.9 & 51.5 & 86.2 & 41.4 \\
\end{tabular}

*: only to be used for early retirement or sabbatical leave.

** 70 hours annually on fulltime basis (in proportion for part timers), to spend at onese discretion on for example: personal leave savings, educational goals, additional annual leave, care leave, or to cash out. Emergency leave allows employees to take paid leave in very unusual circumstances that prevent them from going to work, f.i. in the early stages of family caregiving. Short term care leave is mainly meant for short term caring, up to 2 weeks.

Table 4 describes the familiarity and use of formal support arrangements, i.e. the company policies, benefits and programs. The CC offers four arrangements that are not included in the package of the financial company. Of these four measures employees are most familiar with the unpaid leave, which is not used much. (Temporary) reduction in working hours is used most, especially by the high intensity caregivers. Very little use is made of special care leave and (temporary) reduction in tasks. The FC offers two unique arrangements, teleworking and personal budget. In 2011 the company has started the project Work Remotely (in Dutch: $\mathrm{HNW}=$ Het Nieuwe Werken). An important feature of HNW is the possibility of teleworking also called work shifting. Teleworking allows employees to work at home or at a local telework center one or more days per week using communication tools, such as such as phone, fax, modem, internet teleconferencing, e-mail or IM, to perform work duties from a remote location. Both teleworking and the personal budget arrangement are applied extensively by all three subgroups, but less by the high intensity care group.

The CC and FC have six arrangements in common. In both companies the majority of employees are familiar with these measures, and most well-known are part time work and personal saving scheme. In general, it is noticeable that informal caregivers in the CC report a relatively greater use of all arrangements (accept for long (unpaid) care leave) than the non-informal caregivers. Furthermore, in the $\mathrm{CC}$ most utilized by all three subgroups are part time work and flexible hours, the last one being slightly more used by both informal 


\section{Macrothink}

International Journal of Human Resource Studies

ISSN 2162-3058 2015, Vol. 5, No. 3

caregiver groups. Both CC informal care groups make more often use of emergency leave compared to the non-informal care group.

In the FC both informal care groups, compared to the non-informal care group, make more use of: part time work, short term care leave, and long (unpaid) care leave, but less of: emergency leave, flexible hours and personal saving scheme.

All three CC groups make more use of part time work compared to the FC employees, which probably is related to the high number of female workers in the $\mathrm{CC}$. The $\mathrm{CC}^{\text {es }}$ caregivers make more use of emergency leave and flexible hours, while the FC caregivers utilize more often short term and (unpaid) long care leave.

\subsection{Informal support arrangements}

An important indicator of the presence of informal support arrangements is the organizational work-home culture. Table 5 shows the mean scores on the five WHC variables per group and per company. For both companies no significant differences were found between the scores of the three distinguished groups. In the $\mathrm{CC}$ the scores on the colleague support are slightly higher than the scores on both other support scores. In the FC, in the non-informal and high intensity care group, organizational support is perceived as the most present.

The results on other indicators of informal support are reported in table 3. As can be seen, not all responders were aware of their role as caregiver. Of those well aware of being an unpaid caregiver not all informed their supervisor or colleagues, for various reasons but mainly because they did not feel the need to do so. 
Table 5. Mean scores on Work-Home culture variables of the non- $(0 \mathrm{hrs} . / \mathrm{wk}$. $)$, the low $(<8$ hrs./wk.) and high intensity care group ( $\geq 8 \mathrm{hrs}$./wk.) from the care company (CC) and the financial company (FC).

\begin{tabular}{|c|c|c|c|c|c|c|c|c|}
\hline \multirow{2}{*}{$\begin{array}{l}\text { Variable } \\
\text { (range 1-5) }\end{array}$} & \multicolumn{4}{|l|}{$\mathrm{CC}^{*}$} & \multicolumn{4}{|l|}{$\mathbf{F C} * *$} \\
\hline & $\begin{array}{l}0 \\
\mathrm{hrs} / \mathrm{wk}\end{array}$ & $\begin{array}{l}<\quad 8 \\
\text { hrs/wk }\end{array}$ & $\begin{array}{l}\geq 8 \\
\text { hrs/wk }\end{array}$ & $\mathrm{F}$ & $\begin{array}{l}0 \\
\mathrm{hrs} / \mathrm{wk}\end{array}$ & $\begin{array}{l}<\quad 8 \\
\text { hrs/wk }\end{array}$ & $\begin{array}{l}\geq 8 \\
\mathrm{hrs} / \mathrm{wk}\end{array}$ & $\mathrm{F}$ \\
\hline & $\mathrm{n}=321$ & $\mathrm{n}=66$ & $\mathrm{n}=59$ & & $\mathrm{n}=499$ & $\mathrm{n}=33$ & $\mathrm{n}=29$ & \\
\hline $\begin{array}{l}\text { Organizational } \\
\text { support }^{1)}\end{array}$ & 3.11 & 3.25 & 3.03 & 1.91 & 3.60 & 3.48 & 3.57 & 0.49 \\
\hline $\begin{array}{l}\text { Supervisor } \\
\text { support }^{1)}\end{array}$ & 3.61 & 3.69 & 3.58 & 0.37 & 3.51 & 3.52 & 3.44 & 0.19 \\
\hline $\begin{array}{l}\text { Colleague } \\
\text { support }^{1)}\end{array}$ & 3.73 & 3.82 & 3.71 & 0.97 & 3.55 & 3.41 & 3.43 & 1.67 \\
\hline Time demands ${ }^{2)}$ & 2.59 & 2.63 & 2.57 & 0.10 & 2.71 & 2.92 & 2.65 & 1.05 \\
\hline $\begin{array}{l}\text { Career } \\
\text { consequences }^{3)}\end{array}$ & 2.63 & 2.61 & 2.66 & 0.08 & 2.82 & 2.98 & 3.01 & 1.82 \\
\hline$*$ adjusted for ag & orking & $\operatorname{ars}$; * & djuste & & gende & & & \\
\hline
\end{tabular}

Table 6. Awareness of supervisors and colleagues with unpaid care giving employees in their team in the care company $(\mathrm{CC})$ and the financial company $(\mathrm{FC})$.

\begin{tabular}{|l|l|l|l|l|l|}
\hline \multicolumn{2}{|l|}{ CC } & \multicolumn{2}{l|}{ FC } \\
\hline & supervisor & colleagues & & supervisor & \multicolumn{2}{l|}{ colleagues } \\
\cline { 2 - 4 } \cline { 5 - 6 } & $\mathrm{n}=38(\%)$ & $\begin{array}{l}\text { n=298 } \\
(\%)\end{array}$ & $\mathrm{n}=72(\%)$ & $\begin{array}{l}\mathrm{n}=434 \\
(\%)\end{array}$ \\
\hline Familiar with concept of unpaid care & 100 & 96.0 & & 93.1 & 92.2 \\
\hline
\end{tabular}




\begin{tabular}{|l|l|l|l|l|}
\hline giving before survey (yes) & & & & \\
\hline $\begin{array}{l}\text { Have you got employees with unpaid } \\
\text { care giving tasks in your team? }\end{array}$ & 84.2 & 52.0 & 18.1 & 18.9 \\
- yes & 13.2 & 18.1 & 66.7 & 49.8 \\
- no & 2.6 & 29.9 & 15.3 & 31.3 \\
- don't know & & & & \\
\hline $\begin{array}{l}\text { If yes: work and } \\
\text { discuss combining }\end{array}$ & 71.9 & 67.7 & 76.9 & 36.6 \\
unpaid care giving & & & 76.9 & \\
\hline \begin{tabular}{l} 
have adequate support measures \\
\hline
\end{tabular}
\end{tabular}

Finally, table 6 gives an insight into the awareness of supervisors and colleagues about the presence of unpaid caregiving co-workers in their team. In both companies almost all supervisors and colleagues are familiar with the concept of unpaid care. However, in both companies about 30 percent of the colleagues does not know whether there are co-workers in their team who provide informal care in their private situation. Supervisors are more aware of having informal caregivers in their team, only $2.6 \%$ of the CC supervisors and $15.3 \%$ of the FC supervisors are not aware of this. Also notable is that only $36.6 \%$ of the FC colleagues discusses the combination of work and unpaid care with their informal caregiving team members, compared to $67.7 \%$ of the CC colleagues.

\section{Discussion}

The current study focused on the formal and informal means of organizational support for employed informal caregivers in a health care company and a financial company in the Netherlands. We investigated the respondents' familiarity and use of the company formal leave policies and their experiences with informal work-home culture aspects that may hinder or support a good balance between employees' work and family lives. As a further indicator of the presence of a supporting culture we examined the awareness of informal caregivers and their direct supervisor and colleagues with unpaid caregiving and whether the informal caregivers informed their superior and co-workers about their caregiving situation. To gain more insight into the informal care situation of unpaid caregivers we explored some characteristics of this situation and employees' experiences in combining employment with unpaid caregiving.

According to the prevailing Dutch definition of an informal carer, the group of informal caregivers was divided into a low-intensity caregiving group, providing informal care for less than 8 hours per week, and a high-intensity care group, with at least 8 hours informal 
caregiving per week. In the $\mathrm{CC}$ and $\mathrm{FC}$ respectively $28 \%$ and $11.1 \%$ of the respondents identified themselves as informal caregiver, the first percentage being above and the second slightly below the mean of $12.5 \%$ of the Dutch employees that, according to Van Kesteren (2009), are combining work with taking care of a partner, relative or good friend. This relative high percentage for the $\mathrm{CC}$ is not an unexpected result as $74 \%$ of the $\mathrm{CC}$ respondents appeared to be working in a caregiver function. Health care professionals, especially nurses, are most likely to be assigned the (parents) caregiver's role in the family (Ward-Griffin 2004). Becoming the family caregiver may seem a 'natural' step for them as they are expected to possess the necessary knowledge and skills to fulfill this role. Our study also revealed that the mean number of different caring tasks per carer and the hours care per week were higher in the $\mathrm{CC}$ than in the FC and a higher percentage of employees from the $\mathrm{CC}$ delivered personal care to their family member. On the other hand, the informal caregivers in the FC spend more hours per week on work and unpaid care together. The FC indeed employs more full-timers than the $\mathrm{CC}$ and the FC part-timers have on average more contract hours than the $\mathrm{CC}$ part-timers. The $\mathrm{CC}$ as well as the FC informal caregivers consider themselves as being fairly well able in combining work and unpaid care responsibilities. Although the FC caregivers experience quite a lot interruption at work due to caregiving obligations, especially compared with the CC caregivers, they do not consider this as a major problem. This probably indicates that the FC provides sufficient opportunity for withdrawal behavior, i.e. lateness, leaving work early, time on telephone, being part of the rituals and routines that characterize its organizational culture (Pettinger 2010). This may result in a smaller inter-role conflict between work and caring responsibilities (Hammer, Bauer and Grandey 2003).

In total 12 different types of workplace policies were offered to the employees at the time of our study, ranging from six measures to cover planned occurrences (no. 2, 3, 6, 8, 9, and 10), one measure to cover unplanned occurrences (no. 4) and five carer-friendly working arrangements (no. 1, 5, 7, 11, and 12). Neither organization offers special support measures for carers as financial benefits, information programs, counseling or support groups. Further we can state that only three policies are created specifically for caregivers (nr. 2, 3 and 9), although also used by a very small percentage (between 1.9 and $5.0 \%$ ) of employees who refer to themselves as non-carer. The other measures are applicable to all employees and used as such. In the light of this the most interesting question is which measures are relatively more often used by caregivers compared to non-caregivers. Remarkable is that in the FC the caregivers, especially the high intensity group ( $>8 \mathrm{hrs}$./wk.), only profit more by part time working, and taking short and long term care leave. On the other hand, the CC carer, compared to his non-caring colleague makes more use of all but one arrangement, with the exception that unpaid leave is remarkably little used by the high intensity carer group. Working part-time, as the majority of the $\mathrm{CC}$ workers do, probably means that taking up planned care leave, especially unpaid leave, is not so obvious. More salvation is found in flexible solutions such as working flexible hours, and temporary reduction in working hours and tasks. This probably provides them with the opportunity to perform their very varied spectrum of caring tasks, ranging from domestic help to personal care. This finding contradicts the assertion of Cullen and Gareis (2011) that flexible working arrangements are difficult to practice in jobs that are highly client-dependent and in organizations with many 
part-time workers, being typical characteristics of health care organizations.

It is fair to state that in our companies the employees of all three distinguished groups appreciate largely the organizational, supervisor and colleague support they receive in combining work with informal care duties. Also they did not experience extreme negative career consequences and high company expectations concerning their time investment on the job (=WHC hindrance factors). The study of Dikkers, Geurts, Den Dulk, Peper, Taris and Kompier (2007) in a sample of 1,179 respondents, derived from three Dutch organizations (i.e. a manufacturing company, a public and a financial organization), reported WHC scores being less positive than the mean scores in our study.

In both high intensity care groups in the $\mathrm{CC}$ and $\mathrm{FC}$ and in the low care group in the $\mathrm{CC}$ only approximately 10 percent of the participants were not aware of their role as caregiver before completing the questionnaire, whereas about 33 percent of the FC caregivers who provided informal care for less than 8 hours per week did not regard themselves as a carer. Probably for this group especially it is not yet an issue to make a distinction between ,just visiting a loved one and keeping him/her company ${ }^{\text {ee }}$ and ,taking care ${ }^{\text {ee }}$ of him/her in a more structural manner. On the other hand, the $\mathrm{CC}^{\text {es }}$ employees in the low intensity group consider themselves more as informal caregivers. It is possible that providing support to a relative/friend is viewed more by them in the extension of the job they do as a professional health care worker. Our finding that they inform their supervisor and colleagues sooner than their counterparts in the FC is probably a consequence of their awareness.

In both companies the supervisors are more aware of the fact that they have subordinates with unpaid care in their team than the colleagues. Striking is that, compared to the $\mathrm{CC}$, only a relatively small part of the FC colleagues $(36.6 \%)$ that know of the care giving situation of their co-workers discusses this situation with them. This might be an indication for a less supportive work environment, which is indeed visible in the lower scores in the FC on colleague support.

Our findings should be considered in the light of some study limitations. First, it may be possible that the relatively low response rate affects the internal and external validity. Presumably the response rate in our study was a result of using digital questionnaires. In other studies (Kwak and Radler 2002) this disadvantage of web surveys resulting in low response rates was confirmed. Opposed to this, web surveys have also advantages such as a smaller turnaround time, lower-item non-response and lower costs. The timing of our data collection could possibly have kept the response rate low. The questionnaire was offered mid-June, with two weeks ${ }^{\text {ee }}$ time to respond, as the holiday season was just starting. Also, a selective (non-) response cannot be ruled out. The ratio between the number of informal and non-informal caregivers among our respondents may differ from the ratio in the population invited to participate. It is not clear if, on the one hand, informal carers were triggered by the research topic to fill in the questionnaire, or, due to for example a lack of time in their already busy schedule, did not respond.

In the $\mathrm{CC}$ the problem of selective (non)-response probably even plays a larger role. In both companies all employees were invited by email to participate in the survey. However, not all 
CC workers had direct access to a computer at work with their own work email address. This group was informed about the research by their direct supervisor who asked them personally to participate and gave them their own access code to the digital questionnaire on the organizational intranet. They were given the opportunity to fill in the questionnaire at work or at home. This divergence in the recruitment procedure may have caused the notable difference in response rate between the $\mathrm{CC}$ and the $\mathrm{FC}$. As a result, we were forced not to compare the scores of both companies directly, but to perform descriptive analyses for each organization separately, with the restrictions entailed.

As the number of informal caregivers is expected to increase, it becomes insurmountable that a policy and practical support system has to be developed to help employees to continue to care while maintaining a good quality of life. Working carers are a heterogeneous group, employed in different types of workplaces, with varying caring situations and preferences for different forms of company-level policy measures, as was stressed in our study. Organizations best choose a broad spectrum of policy measures by which they do not only cover for planned occurrences. The caregiver of a chronically ill/disabled, in many cases elder person, in contrast to the child carer, is likely more often confronted with sudden and unpredictable events and therefore more in need of possibilities for unplanned leave. To meet this requirement for flexibility the organization must strive for an individually tailored package and customized solutions based on a balance between formal provisions and informal flexibility. The formal leave system must be reinforced, as it were, by the informal organizational culture. The first step in attaining this is making caregiving employees aware of their status as a working carer, together with increasing the awareness and understanding of direct supervisors and colleagues, the first ones being an important medium of informal arrangements. A further step is to formalize the discussion on family care and work-home balance more, for example by making it a permanent topic that is raised in employees ${ }^{\text {ee }}$ performance appraisal. Our study showed that only three policies specifically are aimed at informal caregivers and that both companies offered no special support measures. To assist the caregivers in their tasks one can think of free counseling on dealing with care issues and establish care self-help groups in the organization. To directly support their caring activities the employer may provide the carer with information about caring and available care services, or even help them to find appropriate care services or contract care services that staff can avail of.

\section{Conclusions}

Given the limitations, particularly the relative low response rate of the care company, the most striking differences between the informal caregivers working in the health care company $(\mathrm{CC})$ and those in the financial company $(\mathrm{FC})$ are that in the $\mathrm{CC}$ they are greater in number; are more of the female sex; work more in part-time jobs; perform more different types of caring tasks, especially personal care; and they experience less interruptions at work. In both companies the informal caregivers experience no real problems in combining work and unpaid care. Compared to their non-caring colleagues, the $\mathrm{CC}$ informal carers have a relatively greater use of all but one (i.e. unpaid care) formal arrangements and the FC carers only make more use of three measures. Both the $\mathrm{CC}$ and $\mathrm{FC}$ caregivers appreciate the support 
from the organization, supervisor and colleagues and are not really hampered by negative career consequences and high company expectations concerning their time spent at work.

Furthermore, both companies do not assist their informal caregivers with specific support measures that particularly are useful in the changeable caring situation of the chronically ill and/or disables family member or close friend. An important condition for informal caregivers to perform adequately at their work is that the care problems at home are properly regulated. The organization can even help in finding means in which home/community care services are provided and organized in ways that better support working carers. To achieve this, employers need to be conscious that these are important steps in retaining their staff for the future and ensure work participation of a growing part of the labor force.

\section{References}

Airey, L., McKie, L. \& Backett-Milburn, K. (2007). Women's experiences of combiningeldercare and paid work in the Scottish food retail sector. Health Sociology Review, $16,292-303$.

Anderson, R. (2003). Working carers in the European Union. In S. Harper, (Eds.), Families in ageing societies (95-113). Oxford: Oxford University Press.

Arksey, H. (2002). Combining informal care and work: supporting carers in the workplace. Health and Social Care in the Community, 10, 151-161.

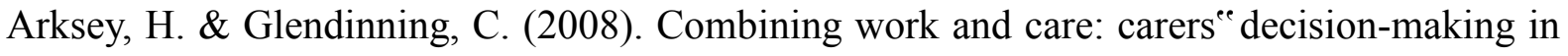
the context of competing policy pressures. Social Policy \& Administration, 42, 1-18.

Barr, J.K., Johnson, K.W. \& Warshaw, L.J. (1992). Supporting the elderly: workplace programs for employed caregivers. The Milbank Quarterly, 70, 509-532.

Behson, S.J. (2005). The relative contribution of formal and informal organizational work-family support. Journal of Vocational Behavior, 66, 487-500.

Boer, de A., Schellingerhout, R. \& Timmermans, J.M. (2003). Mantelzorg in getallen.Den Haag: Sociaal en Cultureel Planbureau.

Boer de, A., Broese van Groenou, M. \& Timmermans, J. (2009). Mantelzorg. Een overzicht van de steun van en aan mantelzorgers in 2007. Sociaal en Cultureel Planbureau, Den Haag.

Chappel, N..L \& Reid, R.C. (2002). Burden and Well-being among caregivers: Examining the distinction. The Gerontologist, 42, 772-780.

Cullen, K. \& Gareis, K. (2011). Company initiatives for workers with care responsibilities for disabled children or adult. European Foundation for the Improvement of Living and Working Conditions, Dublin.

Dikkers, J., Geurts, S., Dulk den, L., Peper, B. \& Kompier, M. (2004). Relations among work-home culture, the utilization of work-home arrangements, and work-home interference. Int. J of Stress Management, 11, 323-345. 
Dikkers, J.S.E., Geurts, S.A.E., Dulk den, L., Peper, B., Taris, T.W. \& Kompier, M.A.J. (2007). Dimensions of work-home culture and their relations with the use of work-home arrangements and work-home interaction. Work \& Stress, 21, 155-172.

Eurostat. (2009). Reconciliation between work, private and family life in the European Union,Luxembourg: Publications Office of the European Union. [http://epp.eurostat.ec.europa.eu/cache/ITY_OFFPUB/KS-78-09-908/EN/KS-78-09-908-EN. PDF].

Farfan-Portet, M., Popham, F., Mitchell, R., Swine, C. \& Lorant, V. (2009). Caring, employment and health among adults of working age: evidence from Britain and Belgium. European Journal of Public Health, 20, 52-57.

Fine, M.D. (2012). Employment and informal care: sustaining paid work and caregiving in community and home-based care. Ageing Int, 37, 57-68.

Hammer, L.B., Bauer, T.N. \& Grandey, A.A. (2003). Work-family conflict and work-related withdrawal behaviors. Journal of Business and Psychology, 17, 419-436.IBMRSPSSR Statistics. (2011). Version 20.0. IBM Corporation.

Kesteren van, D. (2009). Expertisecentrum wil mantelzorg bespreekbaar maken op het werk:Een taboe van twee kanten. SER Magazine: Den Haag.

Kotsadam, A. (2011). Does informal eldercare impede women's employment? The case of European welfare states. Feminist Economics, 17, 121-144.

Kwak, N. \& Radler, B. (2002). A comparison between mail and web surveys: Response pattern, respondent profile, and data quality. Journal of Official Statistics, 18, 257-273.

Lewis S. (1999). Work-family arrangements in the UK. In L. den Dulk, van Doorne-Huiskes,

A. \& J. Schippers (Eds.), Work-family arrangements in Europe (41-56). Amsterdam: Thela-Thesis.

Lilly, M.B., Laporte, A. \& Coyte, P.C. (2007). Labor market work and home care's unpaid caregivers: A systematic review of labor force participation rates, predictors of labor market withdrawal, and hours of work. The Milbank Quarterly, 85, 641-690.

McBride-King, J. (1999). Caring about caregiving: the eldercare responsibilities of Canadian workers and their impact on employers, ON, Conference Board of Canada, October, Ottowa.

Mezzo. (2012). Regeerakkoord Rutte II en de gevolgen voor de informele zorg [http://www.mezzo.nl/regeerakkoord_nieuw_kabinet]

Oudijk, D., Boer de, A., Woittiez, A., Timmermans, J. \& Klerk de, M. (2010). Mantelzorg uit de doeken. Den Haag: Sociaal Cultureel Planbureau.

Pavalko, E.K., \& Henderson, K.A. (2006). Combining care work and paid work. Do workplace policies make a difference?. Research on Aging, 28, 359-374.

Pettinger, R. (2010). Organizational behavior. Performance management in practice. London 


\section{Macrothink \\ International Journal of Human Resource Studies \\ ISSN 2162-3058 2015, Vol. 5, No. 3}

and New York: Routledge, Taylor \& Francis Group.

Philips, J., Bernard, M. \& Chittenden, M. (2002). Juggling work and care. The experiences of working carers of older adults. Bristol: The Policy Press.

Rutte, M. \& Samson, D. (2012). Bruggen slaan. Regeerakkoord VVD - PvdA. Den Haag: Rijksoverheid.

Thompson, C.A., Beauvais, L.L. \& Lyness, K.S. (1999). When work-family benefits are not enough: the influence of work-family culture on benefit utilization, organizational attachment, and work-family conflict. Journal of Vocational Behavior, 54, 392-415.

Vroome de, E.M.M., Smulders, P.G.W. \& Houtman, I.L.D. (2010). Longitudinale studie naar oorzaken en effecten van presenteeism. Gedrag \& Organisatie, 23, 194-212.

Ward-Griffin, C. (2004). Nurses as caregivers of elderly relatives: Negotiating personal and professional boundaries. Canadian Journal of Nursing Research, 36, 92-114. Work and Care Act (2013) [

http://wetten.overheid.nl/BWBR0013008/geldigheidsdatum_16-04-2013]

Yeandle, S., Wigfield, A., Crompton, R. \& Dennett, J. (2002). Employed carers and family-friendly employment policies. Bristol: The Policy Press.

\section{Copyright Disclaimer}

Copyright for this article is retained by the author(s), with first publication rights granted to the journal.

This is an open-access article distributed under the terms and conditions of the Creative Commons Attribution license (http://creativecommons.org/licenses/by/3.0/). 